\title{
Zhang Guangyu and the Pictorial Imagination of Manhua Journey to the West
}

Manhua Journey to the West is an entertaining, colorful long-form manhua with a comical storyline, but grounded in reality for its penetrating satirical treatment of inflation, forced recruitment of soldiers, rigid ideological training, and the duplicity of the Japanese surrender. This is what makes for good manhua!

- HeN, COMMERCE DAILY (SHANGWU RIBAO, CHONGQING), NOVEMBER 25, 1945

The artist uses the satirical tenor of manhua to probingly turn these perverse phenomena into images for the gaze of all Chinese people, awakening the souls of every Chinese person and reminding them never to forget the crimes and sorrows of the war. Manhua Journey to the West is thus more than a manhua exhibition. It is a history of modern Chinese society, a milestone for China's War of Resistance.

- HSIN-MIN BAO WANKAN (XINMIN BAO WANKAN, CHENGDU), FEBRUARY 7, 1946

Mr. Zhang has adapted the experience of Tripitaka's journey west for the Buddhist sutras, or in this case the Book of Heaven [Tianshu], to relate the process of democratic development. The hardships Tripitaka faces heading west for the sutras are the same as the obstacles facing democracy.

-ZHONG YUAN, XINXIN NEWS (XINXIN XINWEN, CHENGDU), FEBRUARY 8, 1946

I would predict ... two kinds of viewers. One will feel that it is quite good indeed, a feast for the mind and the eye, rather like looking at a beautiful woman. The other kind, beyond finding it attractive and interesting, will get a strange sensation of déjà vu from everything pictured.... He will feel that much of what appears in the illustrations he has either experienced 
himself, or at the very least has heard others talking about. Some are events of the past, others the burning issues of the day.

-YE LINGFENG, NEW LIFE EVENING NEWS (XINSHENG WANBAO, HONG KONG), JUNE 13, 1947

Although what he has drawn is dream-like, it is a dream of reality.... During a time of strangling censorship, when the truth cannot be expressed directly or realistically, artists can only use the pretext of a dreamworld to express their dissatisfaction with reality.

- HUANG MAO, SING TAO DAILY (XINGDAO RIBAO, HONG KONG), JUNE 15,1947

The passages above trace the exhibition of Zhang Guangyu's Manhua Journey to the West from the wartime provisional capital of Chongqing, Sichuan, in late 1945; to Chengdu, several hundred miles west, in early 1946; to the British colony of Hong Kong in the summer of that year. Just three months before the first showing, Japan had surrendered to the Allied forces, bringing to a close its devastating eight-year invasion of China. The end of those hostilities, however, had released longstanding tensions between Mao Zedong's communists, preparing to move out from their wartime bases in the northwest hinterland, and Chiang Kai-shek's Nationalist regime, notorious for its corruption and censorship, now returning from its inland wartime bases to reestablish control over the areas in and around China's major cities. The struggle for dominance would soon explode into three years of brutal civil war.

This is the atmosphere of turmoil and uncertainty that the reviewers of Manhua Journey to the West refer to with the words "history" (lishi) and "reality" (xianshi). For them, Zhang's story reveals the suffering and injustice inflicted on the Chinese people and espouses a vision of democracy denied by the repressive, self-serving Nationalist regime. Their responses to the exhibition affirm the critical consensus on Zhang's Manhua Journey, that it should be viewed as a representation of "Nationalist China in a state of complete moral and social bankruptcy," or in the words of art historian Michael Sullivan, who attended the Chengdu exhibition in 1946, "a satire of contemporary China."

Given Manhua Journey's patently satirical purpose, achieved through a veiled critique of contemporary politics and society, it is no surprise that the reviewers cited above all stress a certain doubleness in Zhang's story and imagery. The ways that they do so, however, are worth a closer look. The pseudonymous Hen (literally "scar"), writing for Chongqing's Commerce Daily, gives due mention to Zhang's "comical storyline" but stresses Manhua Journey's incisive attack on a list of specific wartime and postwar economic, social, and political ills. Similarly, the reviewer for the Chengdu Hsin Min Pao Wankan asks readers to look past the 
"fantastical stories" (huangdan gushi) in both the original, sixteenth-century Journey to the West and the new Manhua Journey to the West to register Zhang's exposé of the trauma behind China's "Pyrrhic victory" (cansheng) over the Japanese. This emphasis on seeing through to underlying social realities appears again in the review by the pseudonymous writer Zhong Yuan, who underlines the allegorical resonance between the quest for Buddhist sutras in the original Journey to the West and China's pursuit of democracy depicted in Zhang's updated version.

Manhua Journey to the West's satirical thrust is not lost on the last two commentators, Ye Lingfeng (1905-75) and Huang Mao, either. Their observations, however, engage Zhang's masterpiece with a slight, but important, difference. Ye, a modernist writer and colleague of Zhang's since the days of Shanghai Sketch, imagines Manhua Journey as perceived by two types of viewers: one distracted by the seductive surfaces of Zhang's drawings and the other able to penetrate those surfaces to detect the artist's social critique. Manhua artist and historian Huang Mao, meanwhile, invokes the metaphor of a dream to describe Zhang's artistic strategy for delivering that critique below the radar of the censors.

More recent commentators have also noted the strong, even extravagant, design elements of Zhang's imagery. One remarks on how Zhang's "exploration into the comparatively systematic language of decorative forms" overshadows his satirical attacks on reality. ${ }^{2}$ Another emphasizes how Manhua Journey unrelentingly reflects "social reality ... despite the surface trappings of a seemingly rather preposterous mythical story" (italics added). ${ }^{3}$ Nowhere, to be sure, do any of these critics, past or present, challenge the idea that one must see through Zhang's seductive, dream-like camouflage to grasp the satirical intent of his masterpiece. But at the same time, the very distraction of these fantastical surfaces prompts an alternative reading of Manhua Journey: specifically, a reading informed by the "pictorial turn." What I mean here is that Manhua Journey can be read beyond satire, as a work of manhua that elaborates and even celebrates the symbiosis of manhua and pictorial magazines in China's treaty ports, and Shanghai in particular, through the first several decades of the twentieth century. More than a veiled indictment of contemporary politics, Zhang's illustrated tale stands out as an allegorical look back at the popular print genre of the pictorial magazine, the medium in which manhua thrived during the interwar years.

Approaching Manhua Journey to the West in this way does more than expand our understanding of one of the most important works of manhua from the 1940s; it marks a watershed moment in the ongoing conjuncture between manhua and pictorial magazines traced by this book. As we will see, Zhang in fact frames his satirical narrative as a pictorial magazine, and in so doing he implicitly celebrates the pictorial form as a mediator of cultural and social modernity. And yet, Zhang told his story at a time when, due to disruptions of wartime, the end of Shanghai's foreign concessions system, and changes in the publishing industry, the era of independent pictorial magazines was in decline. Manhua Journey, then, also offers itself as a valediction, in manhua, for the heyday of the treaty-port pictorial. 
I construct this alternative reading of Manhua Journey through several steps. First, after describing the creation and exhibition of Manhua Journey in the mid1940s, I review the career of Zhang Guangyu as an artist-entrepreneur who over several decades helped invent the relationship between manhua art, which he pioneered, and pictorial magazines, which he prolifically published. I then turn to Manhua Journey to the West itself, explaining its satirical messages and, more to the point, noting how the work as a whole, framed by its opening chapter, can be read as a kaleidoscopic salute to the pictorial magazines Zhang had devoted so much of his career to creating. The conclusion situates Manhua Journey to the West in its transitional moment, as a masterpiece of independent manhua art suspended between the end of the treaty-port era and the new institutions of culture introduced by the communist regime after 1949 .

\section{MANHUA JOURNEY TO THE WEST \\ AS POLITICAL SATIRE}

Zhang Guangyu created Manhua Journey to the West over a period of about four months during the second half of 1945 . The idea of illustrating and adapting the Ming dynasty novel, Zhang writes, came to him while living in Beiwenquan, a quiet resort town on the outskirts of Chongqing, where he settled with his wife and four children in late 1944 after seven years of nomadic life as a wartime refugee. Having exhausted his stock of bedtime stories, Zhang purchased a copy of the original Journey to the West in the nearby town of Beibei, a local cultural center and the wartime site of the relocated Fudan University. He would read one chapter of the novel during the day and then retell it to his children in the evening. This ritual revealed, as he puts it, a level of meaning in the legendary tale he had never before noticed: that of antibureaucratic satire. Specifically, Zhang notes how the Jade Emperor's ruse of granting the Monkey King Sun Wukong the bogus title of Superintendent of Stables "means that the Jade Emperor's Heavenly Palace was riddled with bribery and corruption ... such that Sun Wukong's raising havoc in heaven was a deed of heroic proportions. Likewise, the novel hints at how all the demons and monsters that Tripitaka encounters are, without exception, either relatives of the Jade Emperor or sons-in-law of the Dragon King, sent down to earth as punishment for misdeeds in Heaven."4

Zhang identifies the Jade Emperor's Heavenly Palace with the corrupt and oppressive Nationalist regime of 1945 . He describes his political reinterpretation of Journey to the West as fortuitous, but he was in fact aligning himself with a broad trend in the arts and literature of the Nationalist-controlled regions during the later war years, what Edward Gunn has called "a loosely coordinated shift from resistance literature back to social criticism." In other words, after several years of wartime contribution to the state's goal of national defense, as we saw with Resistance Sketch in chapter 2, creators of fiction, drama, poetry, and visual arts returned 
to an independent, critical stance directed against the misrule of the state authorities, in this case the regime of Chiang Kai-shek. The return to critique was not lost among manhua artists, who had specialized in social and political satire from the 1920 s through the 1930s. For veteran illustrators like Ding Cong, Ye Qianyu, Liao Bingxiong (1915-2006), Huang Yao, and of course Zhang Guangyu, it was a time of exhibitions, both joint and individual, staged in the cities of southwest China: Chongqing, Chengdu, Guiyang, and Kunming. Showing their work in exhibitions, rather than publishing it in magazines or books, was driven by circumstance. With severe materials shortages, lack of printing facilities, and strict censorship making publication in print next to impossible, manhua artists of the time turned to public exhibitions as the most effective way to reach their audiences. ${ }^{6}$

The adaptation of traditional materials in Zhang's Manhua Journey was not unique either. The early years of the War of Resistance had seen extensive experimentation with popular forms, or "putting new wine in old bottles," as a way to spread wartime propaganda among the general populace..$^{7}$ Although this practice tapered off in the Nationalist-controlled areas later in the war as the intended audiences for literature and art moved away from the illiterate or semiliterate and back toward the educated population, manhua artists did not discard traditional forms and techniques but rather employed them in ways that enhanced and refined their own artistic styles. For instance, Ding Cong combined social caricature with the scroll-painting format, complete with colophons, to create his eightfoot-long Images of Today (Xianxiang tu), exhibited in 1944, while Liao Bingxiong's Cat Kingdom (Maoguo chunqiu) was influenced by Chinese folk art. ${ }^{8}$ Huang Yao, meanwhile, adapted the traditional ink wash (shuimo) technique on rice paper to create the sixty-four panels that made up his softly colored but satirically sharp Contradiction Collection (Maodun ji). ${ }^{9}$

As originally exhibited, Zhang's Manhua Journey comprised sixty panels, with color illustrations above the accompanying narrative text, which was written by Zhang Guangyu's younger brother, Zhang Zhengyu, in decorative li style calligraphy (see figure 33). The first showing of Manhua Journey, a preview held November 18, 1945, in Chongqing's Yangtze River Dance Hall (Yangzi jiang wuting), was attended by members of Chongqing's literary and art circles, including manhua artists Ye Qianyu, Wang Zimei, and Huang Miaozi (1913-2012), as well as sinologist John K. Fairbank and his wife, Wilma Fairbank, who was working as a cultural attaché for the United States Embassy. The open exhibition of Manhua Journey was extended twice, which attests to its popularity. The initial public showing, at Chongqing's Sino-Soviet Cultural Center from November 22-26, was prolonged to December 3, and the entire exhibition then moved to another venue in the city to run until December 12. The exhibition in Chengdu two months later, from February 2-8, was also extended for three days due to popular demand. Exhibitions planned for Shanghai and Nanjing in 1946 were banned by the authorities, but the series was displayed once more in Hong Kong in June $1947 .^{10}$ 
FIGURE 33. Zhang Zhengyu (left) and Zhang Guangyu (right) preparing for the

1945 Chongqing exhibition of Manhua Journey to the West.

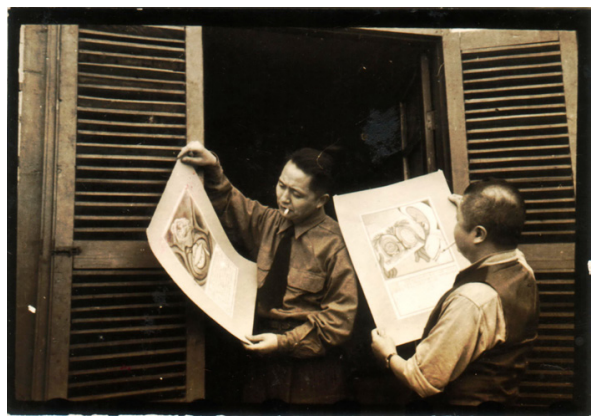

Though unique in form, Manhua Journey to the West invites comparison with several visual and literary genres. The poster Zhang designed for the exhibition calls the work a "color, long-form mythical manhua" (changpian shenhua cai manhua). ${ }^{11}$ In the press, however, Manhua Journey was in at least one instance advertised under a slightly different name, as a "color, long-form mythical picture-story" (changpian shenhua caise lianhuanhua). ${ }^{12}$ The term "picture-story" (lianhuanhua) refers to a popular genre of illustrated storybooks that by the 1930 s offered adaptations of everything from traditional moral tales to martial arts movies. ${ }^{13}$ Manhua Journey's structural affinity to the picture-story genre distinguishes it from the exhibited work of Ding, Ye, Liao, and Huang, which did not depend on long-narrative format. At the same time, the story's ten sections, or hui, each six pages long, resemble the episodic structure of the original Journey to the West. Zhang described this loose episodic structure as modeled after the original novel's "sausage-link" organization, according to which, "if you cut off a length, or add a length, it's still a string of sausages." ${ }^{14}$ Adding further to the open-endedness of Zhang's narrative is that the ten hui comprise what was intended to be the first installment of a series, so the story itself ends inconclusively. ${ }^{15}$ Further resonances with the idiom of a traditional vernacular novel include the introductory couplets introducing each hui, and the semiarchaic linguistic style of the narrative text that accompanies each illustration.

As in the original novel, the various subplots in Manhua Journey come together around a quest: Monkey (Sun Wukong), Pig (Zhu Bajie), Monk Sha (Sha Heshang), and Tang Xuanzang (Tripitaka) travel in search of the Book of Heaven (Tianshu), a treasure whose precise meaning and value Zhang leaves to the reader's imagination. The four pilgrims move through five locales, with characters and events in each place alluding to issues of corruption, oppression, and excess in wartime and postwar society. Moolaland (Zhibiguo), for instance, is an orientalist confection of a country, where paper money grows on government-owned trees and Pig spits up gold ingots at the request of high-ranking political elite. In the Kingdom of Ancient Aegysine (Aiqin guguo), vicious humanoid crows represent minions of the Nationalist police state who delight in arresting and enslaving the populace. The city of 
Dream Hedonia (Meng de kuaile cheng), meanwhile, is a futuristic, aerial pleasure zone of beauty salons, funhouse mirrors, and dance halls restricted to the rich and politically connected-a dig at the exclusive and Americanized lifestyles of Chongqing's refugee elite. From Hedonia, the travelers ride steel-clad zeppelins over the "Qin Puppet" Demon Empire ("Wei Qin" yaoguo), a reference to the Japanese-occupied regions of wartime China. There, Monkey uses his supernatural powers to bomb the Demon Empire into submission, but the group must then flee because the Hedonian leaders determine the foursome to be "dangerous elements" who oppose continued collaboration with the defeated enemy, a policy that the mayor of Hedonia announces at a grand but bogus amnesty ceremony. After a narrow escape, the travelers' shadows are suddenly sucked into a miasmic cloud, symbolizing the black market. Inside the cloud, they land in a fetid pool, where they "fish in troubled water" (hunshui moyu) for "jackpot" carp before being ingested by a gigantic skeleton, whose capacious stomach is stuffed with cash and contraband. The pilgrims break free from the skeleton, return to their bodies, and continue their quest. The story concludes with Monkey impetuously smashing an "evil egg" (niedan) and inadvertently releasing a clutch of serpents. The last of the sixty panels depicts a gigantic Napoleon emerging from a great gust of wind to upbraid Monkey for setting loose these dragonets of fascism, which the Jade Emperor had assigned Napoleon to guard.

\section{ZHANG GUANGYU AND THE MAKING \\ OF MANHUA JOURNEY}

Manhua Journey's elaborate burlesque of wartime figures and events sets it squarely in the genre of political satire. But as I have suggested, the work's lavish visual impact and absurdist storyline point to resonances with the illustrated magazine. The connections between Manhua Journey and the print genre of the pictorial make further sense against the background of Zhang's career over the three decades preceding 1945. Growing interest in Zhang Guangyu over the past decade or so has shown him to be a treaty-port Renaissance man in the field of commercial art: a designer of advertisements, cigarette cards, and calendar posters for companies likes Nanyang Tobacco and British-American Tobacco; a pioneer in modern Chinese furniture design; a costume designer for early film; an innovator in modernizing Chinese-language typography; author of China's first comprehensive book on international commercial design; and, of course, an accomplished sketch and caricature artist. ${ }^{16}$ But if we seek the center of gravity of Zhang's creative identity among all these activities, we find it in his work with pictorial magazines. In fact, the nexus between manhua and pictorials was largely engineered by Zhang, as we can see in a review of his active role in Shanghai's pictorial press.

Turning first to Zhang's early career in pictorials, we discover how he used this medium to construct his public identity as an artist through self-portraits and 
FIGURE 34 . An early signature by Zhang Guangyu, emulating the style of American illustrators. World Pictorial, no. 1 (August 1918).

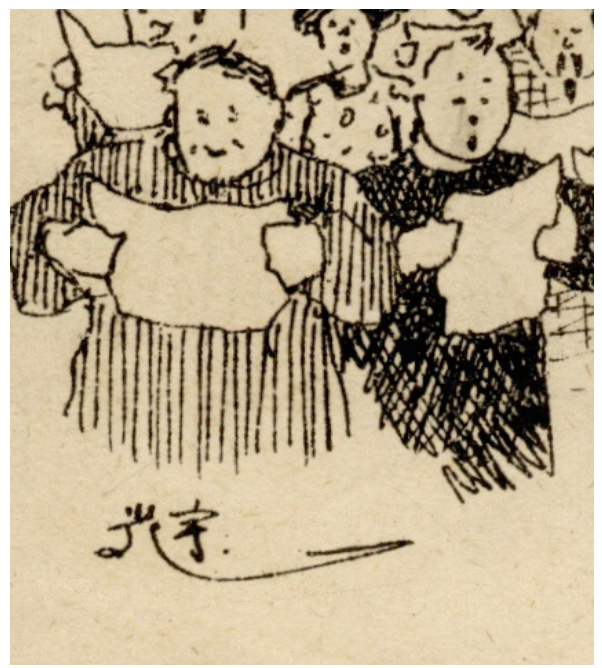

stylized signatures during his apprenticeship at the arts and variety magazine World Pictorial (Shijie huabao) from 1918 to 1919. In World Pictorial, one finds a variety of sketches explicitly depicting Zhang as a Western-style artist. For instance, one pen-and-ink sketch, based on a photograph, shows him in a newsboy cap painting en plein air, brush in hand, palette balanced on his forearm-the very picture, so to speak, of a modern treaty-port painter. It was also at World Pictorial where he invented the pen name Guangyu that he used for the rest of his artistic career. ${ }^{17}$ Breaking with the established tradition of applying a personal stamp to one's artwork as a mark of authenticity, Zhang took up the modern Western convention of signing his magazine illustrations, from cover pictures and advertisements to fashion and current event sketches. His signatures deliberately attract attention with their elaborate flourishes, inspired by popular American illustrators of the time, like Harrison Fisher and Charles Dana Gibson, whom Zhang and his colleagues emulated (see figure 34).

After establishing his professional presence on the pages of World Pictorial, Zhang soon struck out on his own in the rough-and-tumble world of Shanghai's pictorial press. In 1921, he cofounded one of China's earliest film magazines, the Motion Picture Review (Yingxi zazhi). Through the mid-1920s, he worked for the design department of Nanyang Tobacco Company. As noted in chapter 1 , he briefly held an editorial position at Pictorial Shanghai in 1925 before moving on to found and edit China Camera News, the illustrated tabloid that brought together the members of the Manhua Society, with whom Zhang produced the weekly pictorial Shanghai Sketch from 1928 to 1930.

Zhang continued contributing to and editing pictorial magazines through the early 1930s. In late 1929, along with Ye Qianyu and Ye Lingfeng, he founded and 
edited what was to become, behind the Young Companion, the second largest pictorial in Shanghai, Modern Miscellany, the direct successor to Shanghai Sketch. ${ }^{18}$ Several years later, in 1933, Zhang cofounded the illustrated variety magazine Decameron (Shiri tan). After he quit his full-time design work with British-American Tobacco in 1934, his career in pictorials accelerated. During the next three years, before the war with Japan broke out in mid-1937, he worked as chief editor for Van Jan (Wanxiang, 1934) and Thrice-Monthly (Shiri zazhi, 1935-1936); edited two manhua monthlies, Oriental Puck (Duli manhua, 1936-37) and Shanghai Sketch (Shanghai manhua, 1936-37); and coedited with Ye Qianyu the lavish but short-lived manhua magazine Puck (Poke, 1937). ${ }^{19}$ Zhang also contributed extensively to other leading manhua publications of the time. For the most famous and influential of these, Modern Sketch, he designed the cover of the inaugural issue: a bricolage horseman, assembled from the tools of the manhua trade, which became the informal emblem of manhua art and artists.

When artists and writers first turned to creating wartime propaganda full-time following the outbreak of hostilities with Japan in July 1937, Zhang edited Shanghaibased magazines such as "New Life" Pictorial (Xinsheng huabao) and Sino-Japanese War Extra (Kangri huabao) while also serving on the editorial board of National Salvation Sketch. After fleeing to Hong Kong in November 1937, he worked as art director for the Sing Tao Daily (Xingdao ribao) and editor for the affiliated Sing Tao Pictorial (Xingdao huabao). Following a sojourn in Chongqing in 1940-41, he returned to Hong Kong to continue work for Sing Tao Daily, but when the British colony fell to the Japanese, he relocated to the southern Guangdong town of Chikan, where he partnered with his brother Zhengyu to open a restaurant, and then to the city of Guilin in 1943, where he started up a furniture workshop, also with his brother. When Guilin was taken over by the Japanese during the 1944 Ichigo Offensive, Zhang and his family made the hard trek through the interior provinces of Guangxi and Guizhou to Chongqing, where he created Manhua Journey to the West. ${ }^{20}$

\section{FRAMING THE PICTORIAL}

Zhang Guangyu dedicated his career to developing Shanghai's pictorial magazines, and manhua pictorials in particular. That dedication to a print genre carried over into the making of Manhua Journey and indeed provides a path of interpretation that goes beyond the work's satirical message. The point of entry for this rereading is Manhua Journey's opening chapter. Zhang begins his tale with a frame narrative, such that the travels of Monkey, Pig, Monk Sha, and Tripitaka take place as a story within a story. From a practical perspective, the frame story gives Zhang a convenient point of entry into the narrative. From a figurative perspective, much more is going on. The opening chapter in effect encloses the story of political critique, told through the "manhua journey," within a larger story of the print genre that hosted 


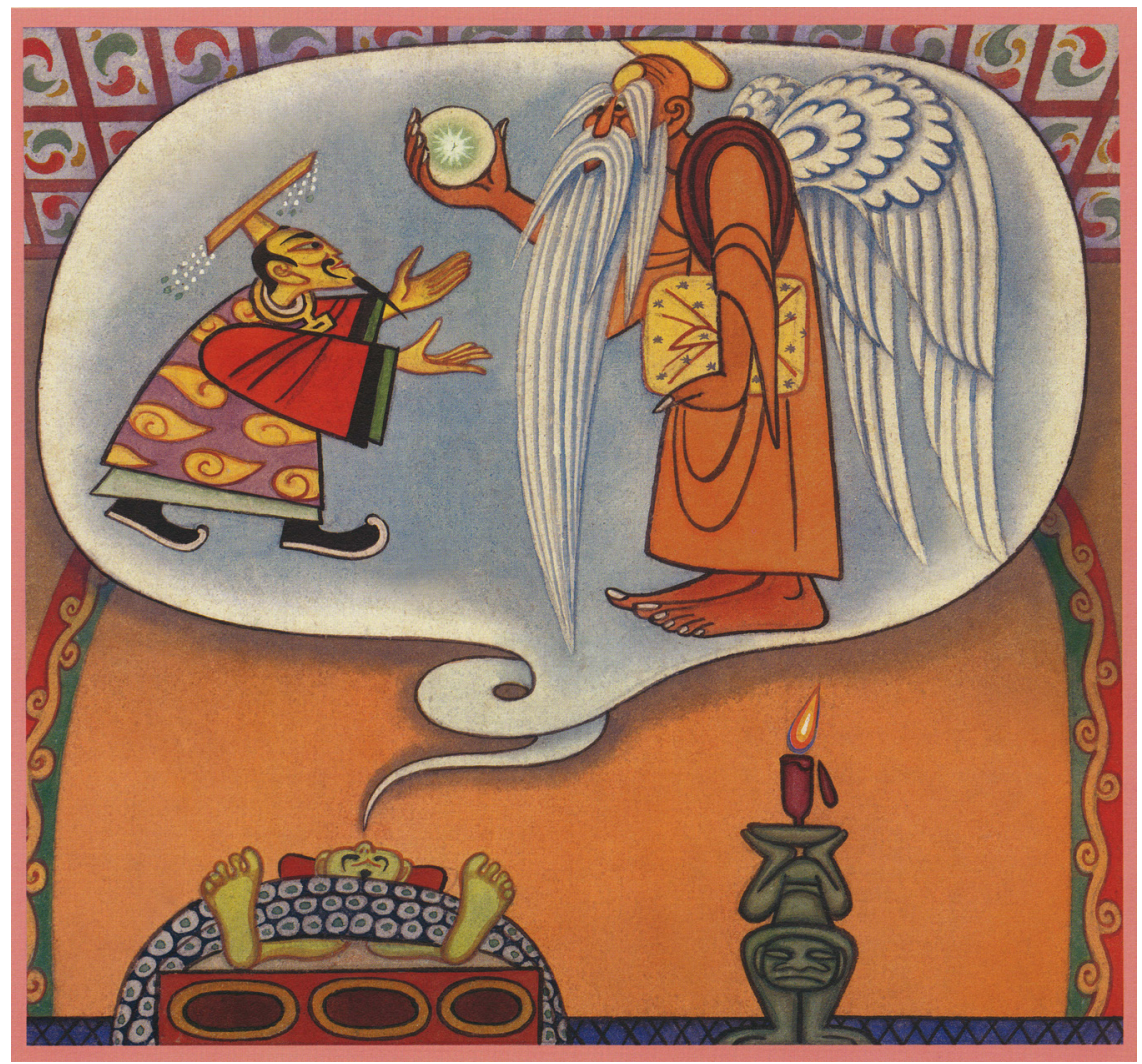

FIGURE 35. The first panel in Manhua Journey to the West.

and defined manhua: the pictorial magazine. At the level of narrative symbolism, then, Zhang "frames" the pictorial genre of manhua within the print genre of the pictorial magazine, making Manhua Journey to the West an elaborate metapicture of the relationship between magazines and manhua, told by a master of both forms.

A close reading of the opening chapter reveals just how Zhang achieves this seemingly improbable feat. The chapter begins with a "clever and capable" king, drawn to resemble an ancient Chinese emperor, dreaming of a visit from the Elder of History (Lishi Laoren), a cartoonishly Westernized character wearing a biblical robe and sporting a golden halo, long beard, and white angel wings (see figure 35 ). ${ }^{21}$ The Elder holds a crystal orb in his right hand. Tucked under his left arm is the Book of Heaven. The Elder hands the orb to the King and announces: "The world is vast and filled with wonders. Your puny kingdom, what does it amount to? I bestow upon you this orb. Look carefully within, and behold the myriad changes!" The King demands to be given the book as well but is rebuffed by the Elder, who promptly vanishes. In the second panel, the King awakens to find that the orb is, in fact, real. It rests in his hands, smooth and featureless on its surface but aglow 
with shifting patterns in its depths. Peering inside, the King sees a mappa mundi (shanhai yuditu) that includes his own country. At first delighted to observe his lands in living detail, the King suddenly grows perturbed upon discovering that the orb also reveals the inner workings of his own court and its officials. Just as he is about to smash the orb, the Elder of History "bursts from a corner of the room in a flash of auspicious light." The Elder tells the King to stay his hand, explaining that the Book of Heaven is, in fact, inside the orb. How, asks the King, can he read the book if it is inside the orb? At this the Elder, with a laugh, points into the orb and tells the King that Monkey and his three colleagues are even now on their way to obtain the book for him from Sukhāvatī, or in Chinese, jile shijie, the Buddhist Western Paradise. ${ }^{22}$

If we look first at the transfer of the orb, Zhang's unsubtle caricature of a biblical elder and a sinicized king points to the manhua artists' belief that their art was, along with the popular pictorial, a Western import. As discussed in the introduction, later scholars with an eye to canonizing manhua have argued for deep historical origins within China for the Chinese cartoon. In 1945, however, manhua artists regarded their craft as having derived from Western models and considered the popularization and evolution of it to be inseparable from the arrival and development of the pictorial magazine. ${ }^{23}$ For instance, in 1935, manhua artist Huang Shiying unequivocally refers to Chinese manhua as "a product of Western culture" originating from Shanghai's Dianshizhai Pictorial, the illustrated newspaper supplement founded in 1884 by the British businessman Ernest Major. ${ }^{24}$ Huang Mao's comprehensive narrative of manhua's development, his 1943 Talks on Manhua Art, tells a similar story. He describes Dianshizhai as "China's first manhua periodical and the first ancestor [shizu] of the huabao," adding that the lithographic process of producing Dianzhizhai in fact "altered the period's mainstream national-style [guohua] mode of illustration." ${ }^{25}$ Both Huangs stress the adoption of Western techniques for manhua, such as the introduction of penand-ink sketching, as well as the influence of Western artists, such as Aubrey Beardsley and Miguel Covarrubias. Perhaps most important, both ground their chronologies in the illustrated serial publications that mediated manhua's development through the early twentieth century, from the newspapers of the late Qing to the tabloids and pictorials of the early twentieth century. Huang Shiying's narration of manhua sees the high points of its development coinciding with the publication of pictorial magazines featuring sketch-style illustration, starting with World Pictorial and Shanghai Puck (Shanghai poke, 1918) in the late 1910s, through Shanghai Sketch at the end of the 1920s, and then on to the mid-1930s boom in manhua pictorials. ${ }^{26}$ Huang Shiying even proposes dividing the maturation of manhua into four periods based on print technology: woodblock, lithography, zinc-plate, and rubber-plate printing. ${ }^{27}$

The transcultural encounter between the Elder and the King, with its transfer of a technology for seeing the world, invokes the pictorial magazine's introduction to 


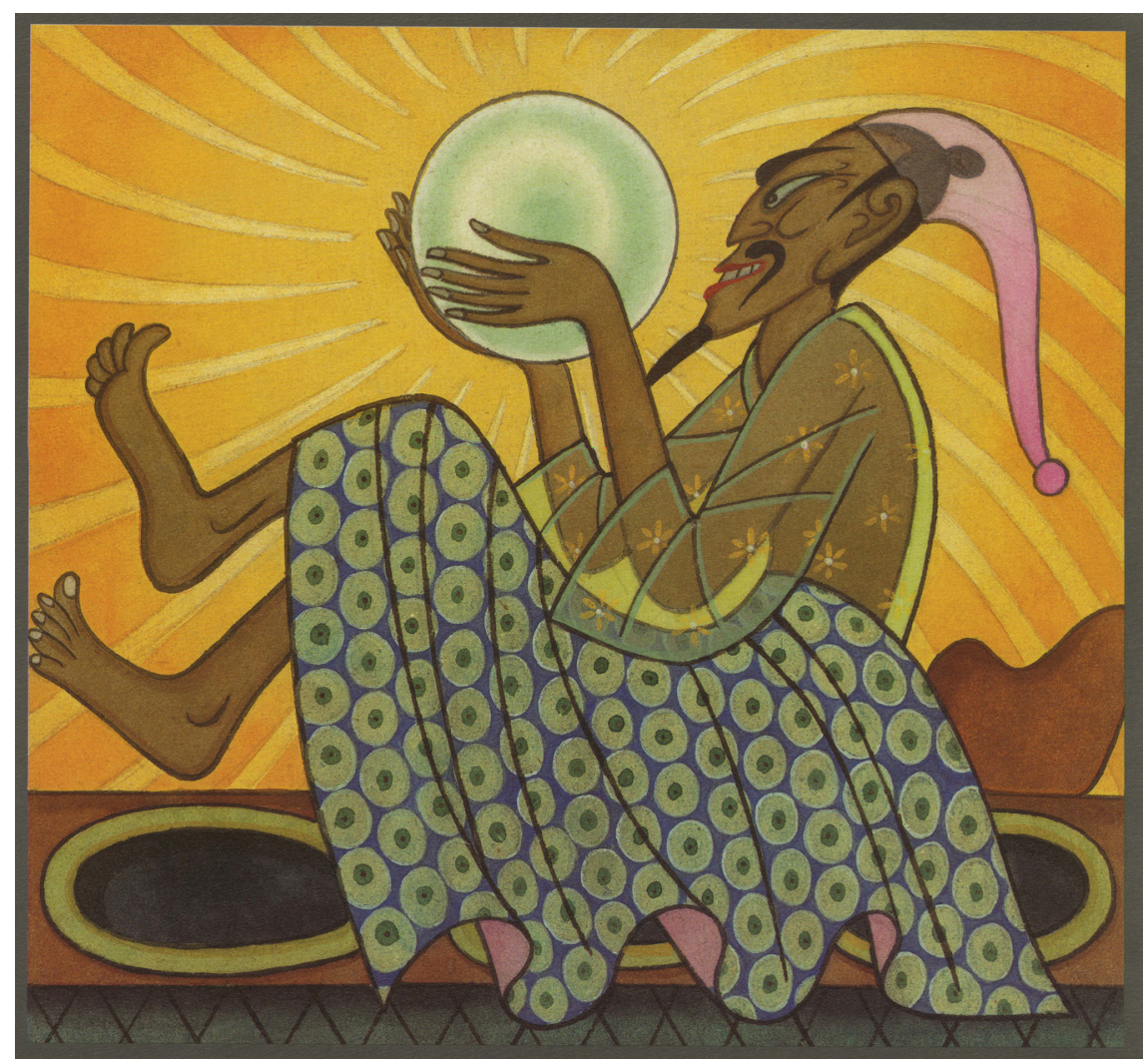

FIGURE 36. The King in bed viewing the orb.

China. Of note here is Zhang's own English-language title for the exhibition: Wonders of Westland. ${ }^{28}$ It is, of course, possible that he chose this title for its pleasant rhythmic assonance, with "Westland" echoing the idea of a "journey west" in the Chinese name for the exhibition. Yet the title also suggests the visual "wonders" of the Western-derived media technology of the illustrated magazine. Such an interpretation may seem farfetched, but Zhang's images in the first chapter, centered on the King's fascination with the orb, in fact replicate the visual relation between readers and pictorial magazines.

Zhang introduces that visual relation from the very first panel, which shows the King in his dream, eyes fixed on the orb, eagerly reaching out to receive it (see figure 35). The Elder, meanwhile, heightens the sense of visual desire by inviting the King to "closely inspect" (zixi guankan) the "kaleidoscope" of images (qianbian wanhua) within. Panel two, a "medium shot" in cinematic terminology, again foregrounds the reader's gaze by showing the King reclining in bed, eyes still fixed on the orb as it radiates golden light (see figure 36). Here, Zhang depicts the King in 


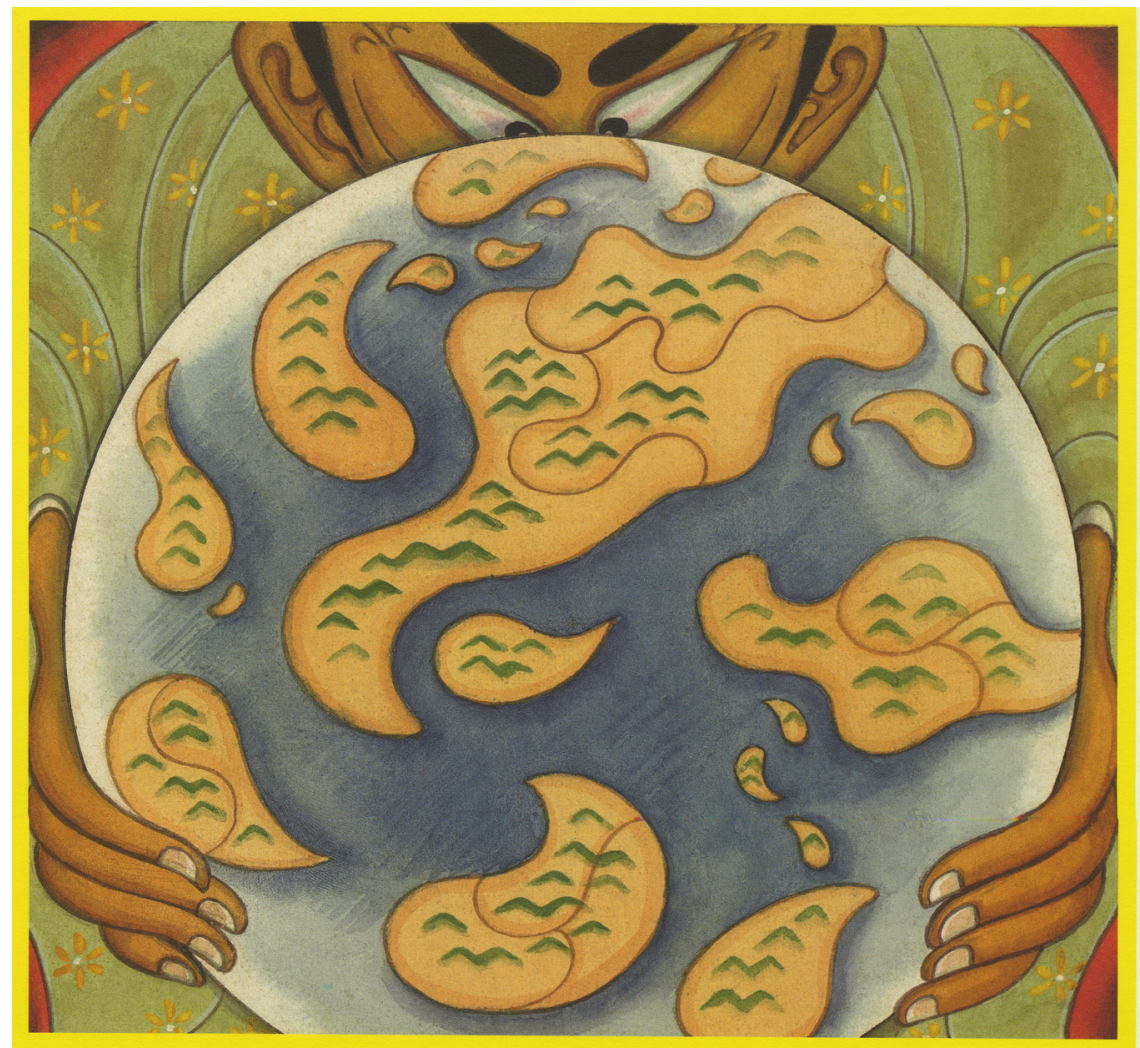

FIGURE 37. The King inspects the mappa mundi, visible within the orb.

the posture of a reader, and more specifically, a reader of leisure visually engaged with this kaleidoscopic device for picturing the world. The third panel zooms in for a close-up of the orb, which fills the frame, magnifying the mappa mundi and positioning the audience of this panel as a mirror image of the King, who peers hungrily into the orb, holding it as if it were a book or magazine (see figure 37 ).

The second half of the six-panel sequence continues to position the orb as a surrogate for a pictorial. In panel five, after the Elder returns to prevent the King from destroying the orb, we are shown the Book of Heaven, floating inside the orb, further suggesting that we identify the orb with printed reading matter. Also in this panel, we again see the King drawn in a posture of reading, but now in profile, just his head and hands visible in the panel's bottom-right corner as he stares intently at the book. In panel six, the illustration shifts to the King's point of view, such that as viewers, we, like him, are gazing into the orb as if our faces are inches from its surface. There we see Monkey, Tripitaka, Monk Sha, and Pig moving through clouds and mountains, setting off on their quest (see figure 38 ). 


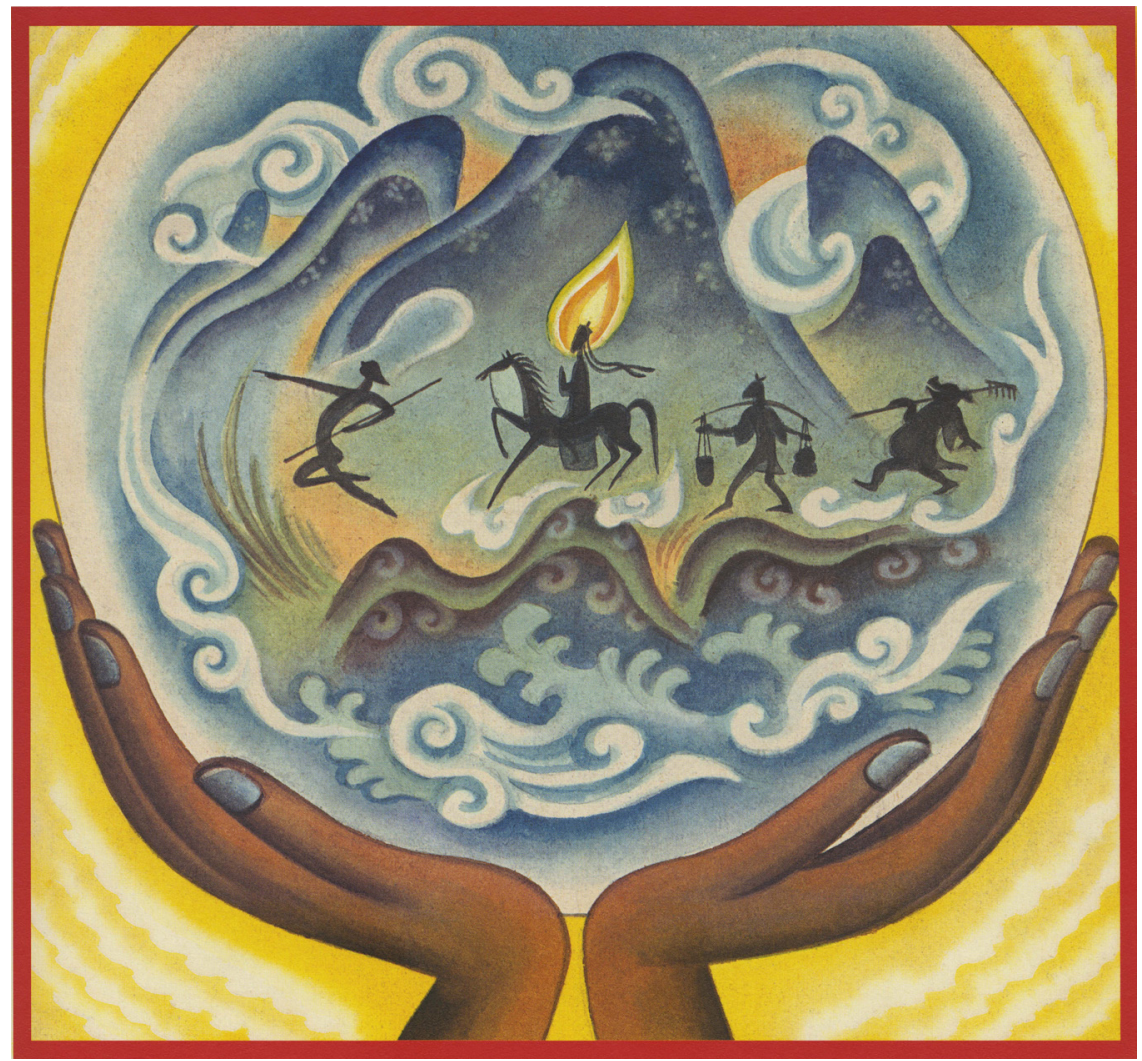

FIGURE 38. Gazing into the orb from the King's point of view.

To review, Zhang begins Manhua Journey with the transfer from "west" to "east" of a wondrous kaleidoscopic device, one designed to picture the world just as serialized pictorial publications, introduced to China in the late nineteenth century, presented readers with varied and fantastic images from all over China and the globe. The story proper of Manhua Journey to the West then occurs within the medium of this visual technology. If we accept this resonance between the orb and the pictorial, what, then, do we make of the Book of Heaven that appears within the orb? The conventional explanation, originally broached by Liao Bingxiong upon the first exhibition of Manhua Journey in Chongqing and picked up by many others, proposes that the book Monkey and company seek is actually the Sutra of Democracy (Minzhu zhenjing). ${ }^{29}$ From that perspective, the story told by Manhua Journey to the West is a political quest of bringing a just and democratic regime to an oppressed people.

Liao's interpretation, which falls squarely on the side of reading Manhua Journey as a political satire, cannot be discounted. But nor does it exhaust the meaning of 
Manhua Journey as a whole. For once we, like the King, enter the world of the orb, we also enter an imaginary space that recreates the cosmopolitan, kaleidoscopic, visual excess of the popular pictorial. From Moolaland and Aegysine to Dream Hedonia and the "Qin Puppet" Demon Empire, Manhua Journey delivers its message via a mélange of imagery that revisits, and even celebrates, the golden age of the Shanghai illustrated magazine. It is in fact the deliberately miscellaneous quality of Zhang's illustration that distinguishes Manhua Journey as a tribute to the art of the pictorial through the art of manhua.

\section{PICTORIAL DOUBLE VISION}

Manhua Journey's opening chapter introduces a scheme of doubled vision: of political satire enframed by the media form of the pictorial magazine. The second and third chapters develop this pictorial double vision by overlaying a lampoon of the Nationalist regime's inflationary economic policy with the sensationalist exoticism of a popular illustrated magazine. Here, the four pilgrims find themselves in Moolaland, where money literally grows on trees and the rulers are cartoon versions of notorious political figures: Minister of Finance H. H. Kung (Kong Xiangxi); his wife, Soong Ai-ling (Song Ailing); one of the famous Soong sisters; and her brother, the high-ranking politician T. V. Soong (Song Ziwen), who was then president of the Executive Yuan. Images of these three figures were, of course, standard fare in the photographs and caricature that featured in pictorial magazines. Zhang Guangyu places Kung and the Soong siblings in fantastical settings that recall these publications' traffic in imagery of celebrity lifestyles and exotic locales. We first see them in a palatial setting of lush tropical vegetation, Chinese-style white marble balustrades, and Middle Eastern architectural details. The composition's focal point is Empress Dai-ling, who reclines on a red and gold modernist scoop chair in a pink outfit inspired by traditional Southeast Asian costumery (see figure 39). The next panel, a long shot of Pig being escorted to the capital of Moolaland, extends the travel motif with another farrago of exotic imagery (see figure 40). A Chinese arched "rainbow" bridge frames a landscape that foregrounds figures in Southeast Asian clothing against a background of mushroom-like structures modeled after Islamist domes, with one of the domes accented by a crescent moon finial.

Zhang applies a similar double coding of political satire and pictorial miscellany to the ensuing chapter, which is an exposé of the Nationalist secret police set in the Kingdom of Ancient Aegysine, a land whose eclectic visual style quotes Nazi iconography, Egyptian Pharaonic art, Disney animation, and traditional Chinese painting. The name of the kingdom, Ancient Aegysine, itself merges the identities of two ancient civilizations, Egypt (Aiji) and China, with the latter linked to First Emperor Qin shihuang, the despotic ruler of the short-lived Qin empire (221-206 $\mathrm{BCE})$, recognized as the founding dynasty of imperial China. Zhang introduces the kingdom's ruler, Pharaoh First Emperor (Falao shihuang), among fascist symbols 


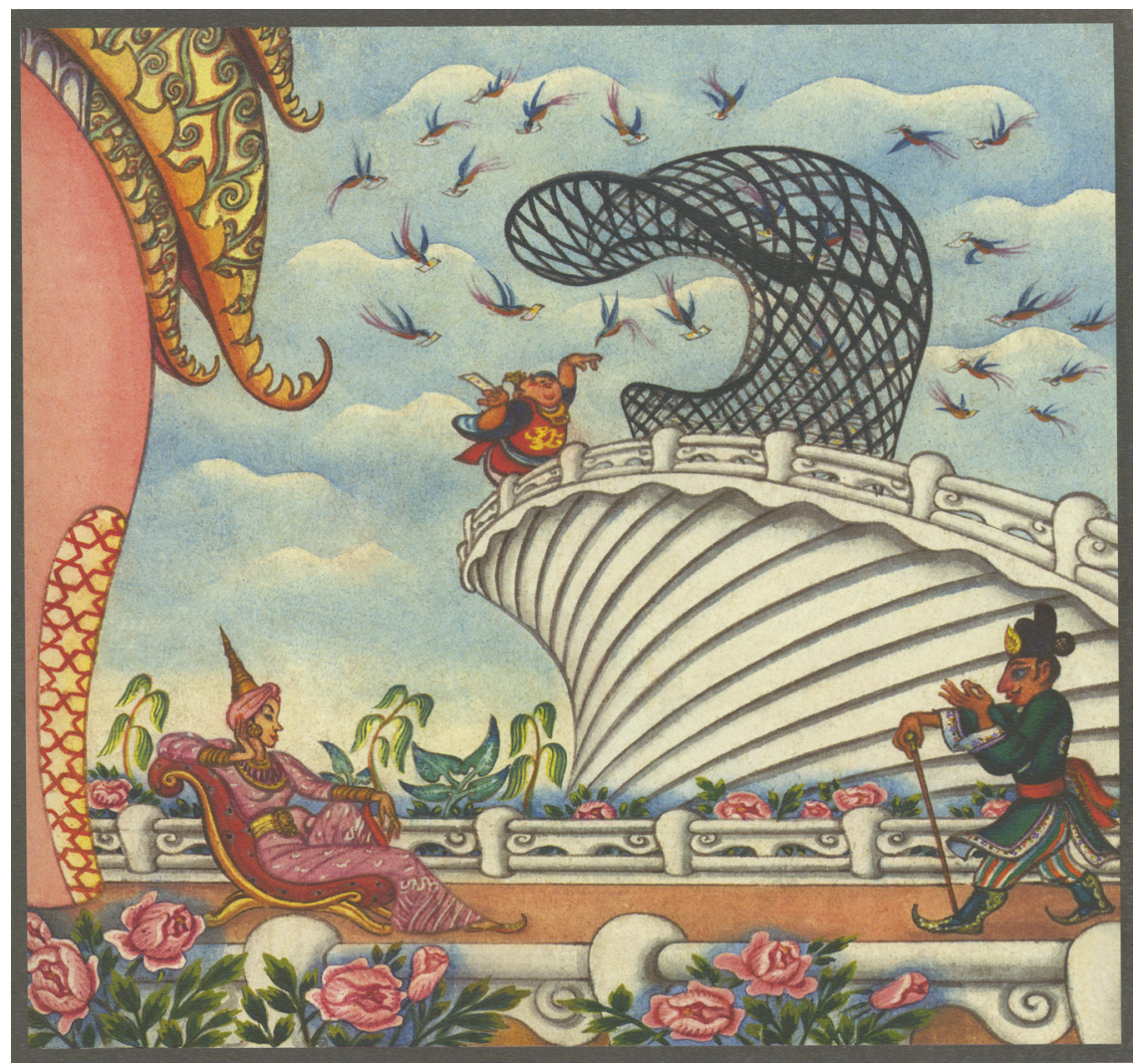

FIGURE 39. The rulers of Moolaland (Zhibiguo).

of the Iron Cross and a pair of heraldic wings resembling those of the Nazi Party eagle. The chapter begins with the capture of Tripitaka and Monk Sha by the pharaoh's secret police and concludes with a titanic battle between Monkey and the pharaoh's evil deputy, Vulture (Maojian ying). The several panels in between layer on more transcultural visual elements. In one, Zhang alludes to Chinese legend when Monkey encounters Meng Jiangnü, the mythical woman who protested the conscription of her husband to build the Great Wall. ${ }^{30}$ Meanwhile, Pig bribes a cigar-smoking humanoid crow loosely modeled after the infamous Jim Crow in Walt Disney's 1942 animated feature Dumbo (see figure 41). Next, Monkey, the Pig, and the hooligan crow race across a field of brown crags protruding from clouds and mist, a manhua adaptation of mountain and cloud tropes borrowed from traditional Chinese landscape painting.

The heterogeneous topoi of the pictorial magazine continue in Zhang's vision of the airborne city of Dream Hedonia, an elaborate satire of elite society in wartime Chongqing. But the imagery of this fanciful city, from space-age floating pleasure 


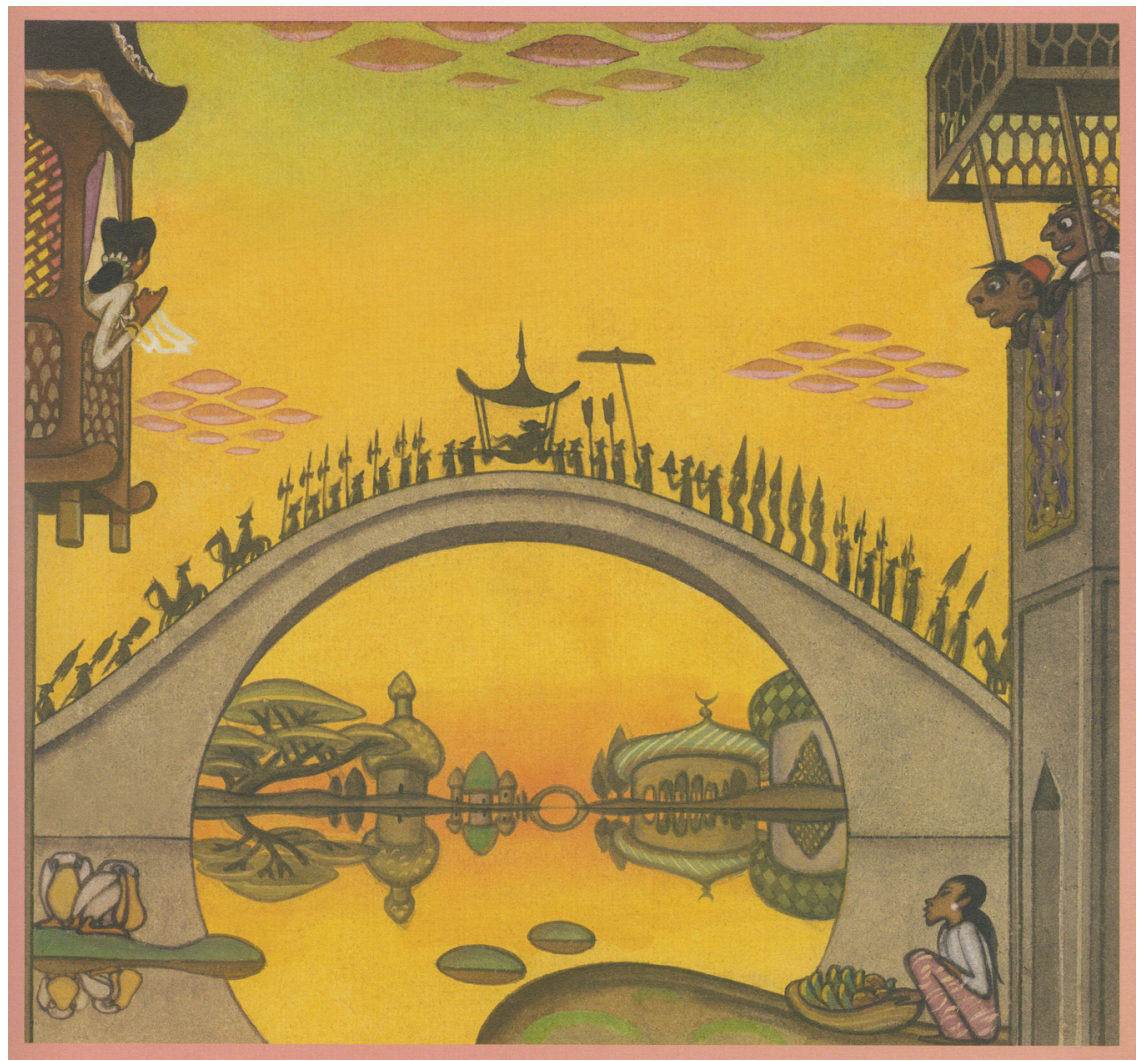

FIGURE 40. The people and buildings of Moolaland.

palaces to modernist beauty salons (see figure 42) and an extravagant masquerade ball, also reflects on the role of the pictorial magazine in defining urban fashion, documenting celebrity lifestyles, and titillating readers with illustrations of the fantastic and futuristic. Chapter 7 turns to another favored subject of the pictorial: the theater. Here, the mayor of Hedonia presents the pilgrims with a Peking opera performance called "Water Curtain Cave" ("Shuilian dong"), featuring an actor as Monkey. Political satire figures in the performance as a struggle over a "staging" of social visions. The play begins with the mayor of Hedonia's pseudomoralistic rendition of an authoritarian society grounded in repression and censorship. The real Monkey, sensing a betrayal of republican ideals, leaps from the audience to disrupt the sham, refashioning the performance on the spot according to his own progressive, humanistic social vision. In chapter 8, Zhang Guangyu parodies the Nationalist government's self-serving postwar compromise with China's former occupiers - the Japanese-and their collaborators. Here, the critique comes as a sequence of photojournalistic images. Zhang, however, renders this typical current 


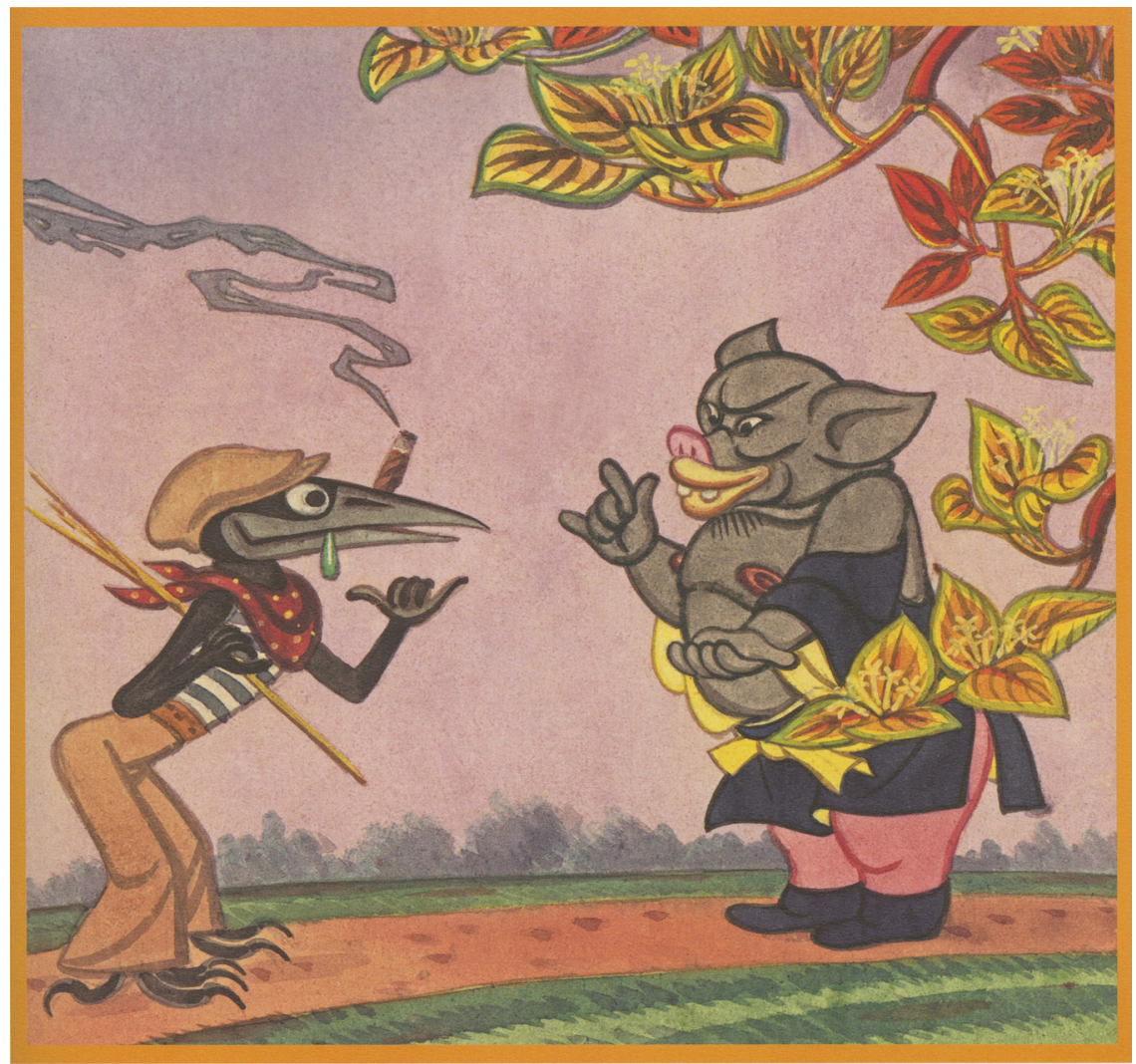

FIGURE 41. Disney-style imagery in Manhua Journey to the West.

affairs content of pictorial magazines into the visual idiom of manhua, laying out a phantasmagoric panorama of an aerial bombing, a sweeping tableau of the surrender of the "Qin Puppet” Demon Empire, and the grotesquely caricatured state pageantry of an amnesty ceremony (see figure 43).

Clearly, Manhua Journey to the West is at one level a veiled indictment of the corrupt and despotic world of the wartime Nationalist regime. But its sensationalistic representations of celebrities, exotic lands, popular entertainment, and current events also make it a tour de force retrospection on the visual aesthetic of Shanghai pictorials of the 1920 s and 1930s, an aesthetic of "layered mediascapes," "fragmented or delirious virtual spaces," and phantasmic dreamworlds that Zhang Guangyu developed throughout his career. ${ }^{31}$ Put another way, to simply comprehend Manhua Journey as expressing its satirical message through the medium of the cartoon diminishes its meaning. Rather, as Marshall McLuhan famously put it, the medium is the message, such that Manhua Journey's satirical subject matter 


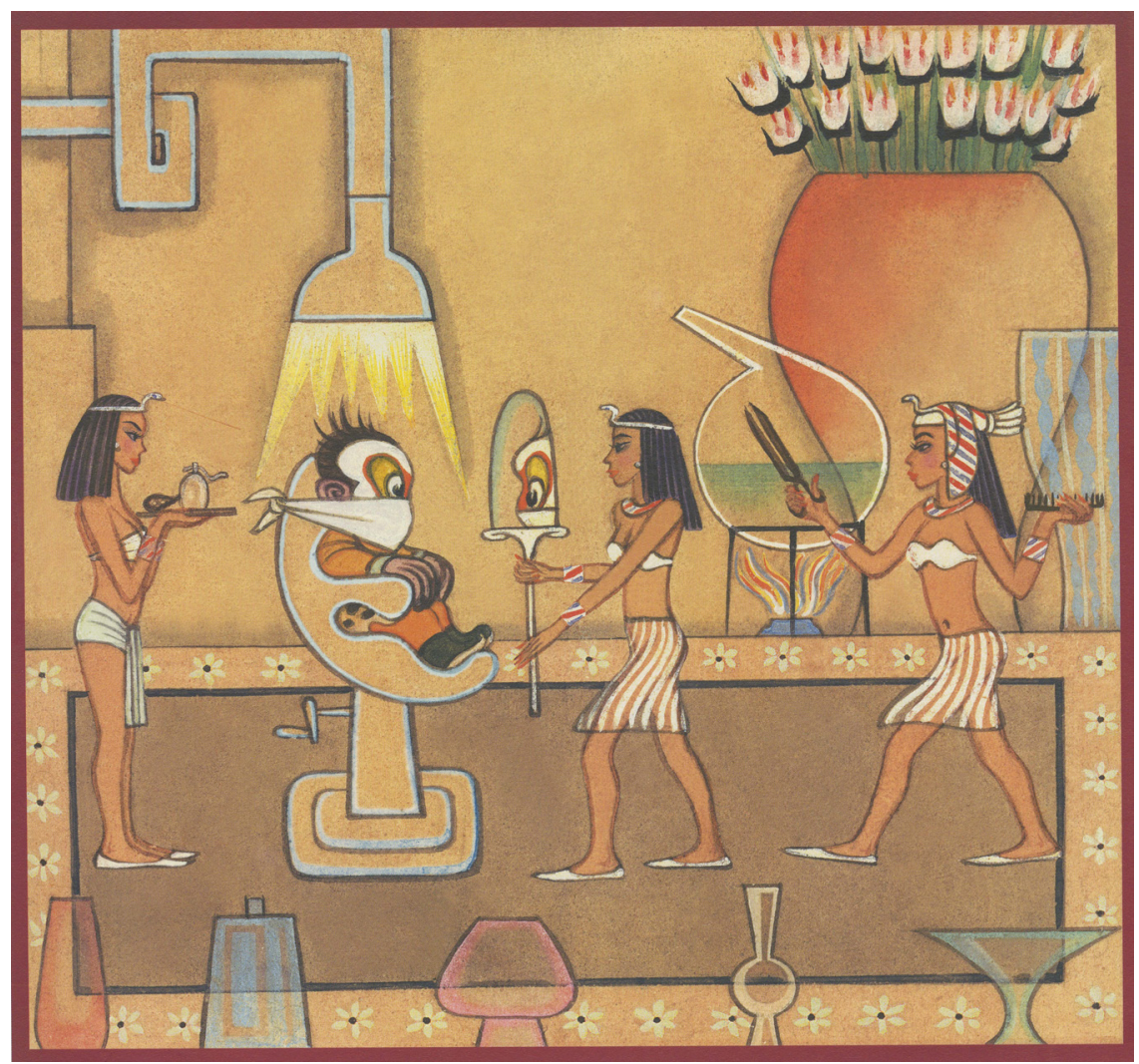

FIGURE 42. Monkey visits a modernist beauty salon in the city of Dream Hedonia.

recedes behind a surfeit of ludic imagery that celebrates the visual world of the pictorial magazine.

\section{CONCLUSION: "THIS IS AN ERA OF MANHUA"}

Shortly after the four pilgrims arrive in Dream Hedonia, the city's mayor orders his secretariat to produce for them a travel guide to the city. Zhang Guangyu shows us Pig reading this guide, depicted as an oversize illustrated magazine whose cartoonish cover features a high-kicking showgirl, a hula dancer, fireworks, and several Hedonian dirigibles (see figure 44). The grinning, drooling, thoroughly delighted Pig announces to Tripitaka, "Master, the Book of Heaven has been right here all along!"32

We might dismiss Pig's response to the guide as a gag; he is, after all, a figure of legendary lust and impetuousness. But why not take Pig at his word? Perhaps Zhang is telling us, through Pig, that, yes, the oversized, manhua-festooned, city 


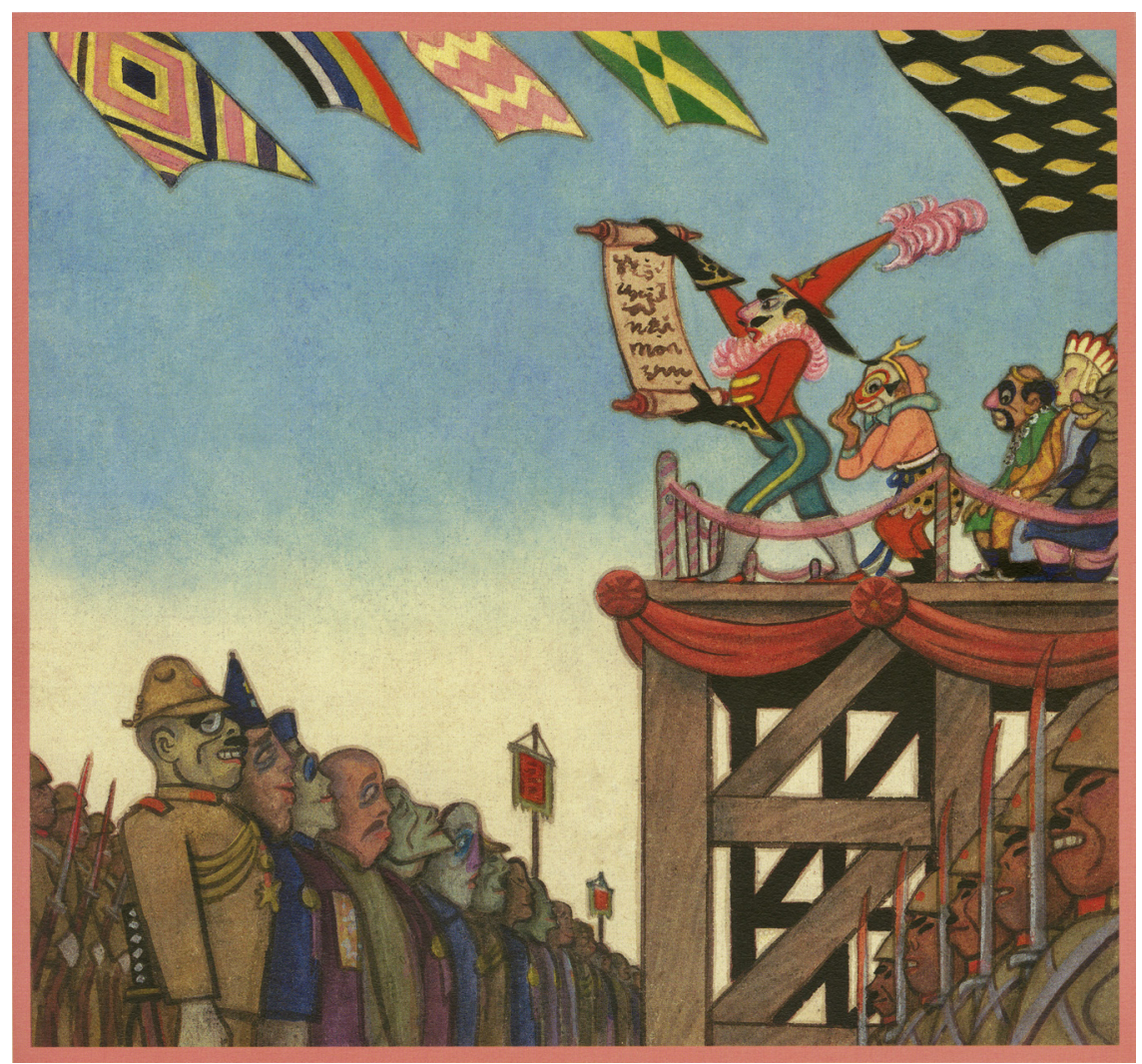

FIGURE 43. The amnesty ceremony following the surrender of the "Qin Puppet" Demon Empire.

pictorial truly is the Book of Heaven and that the crowd-pleasing, colorful genre of the illustrated magazine should indeed be considered the Sutra of Democracy. If so, Zhang would not be the first to take that position. His friend and collaborator in the pictorial business, Shao Xunmei (1906-68), said much the same in late 1934, not long after he had begun collaborating with Zhang to launch a flotilla of high-profile pictorials under Shao's new company, Modern Publications Ltd. ${ }^{33}$ In an article published in Modern Miscellany, Shao explains why he was committing his energies to pictorial magazines rather than "serious publications devoted purely to literature and art." Current literary magazines, Shao observes, are aimed at such a tiny, highly educated segment of the population that "it barely matters if they exist or not." ${ }^{34}$ Moreover, he adds, in contrast to avant-garde literary journals, with circulations from one thousand to at most ten thousand, pictorials like Modern Miscellany and the Young Companion enjoyed print runs reaching sixty thousand to seventy thousand. Shao goes on to express a particular disdain 


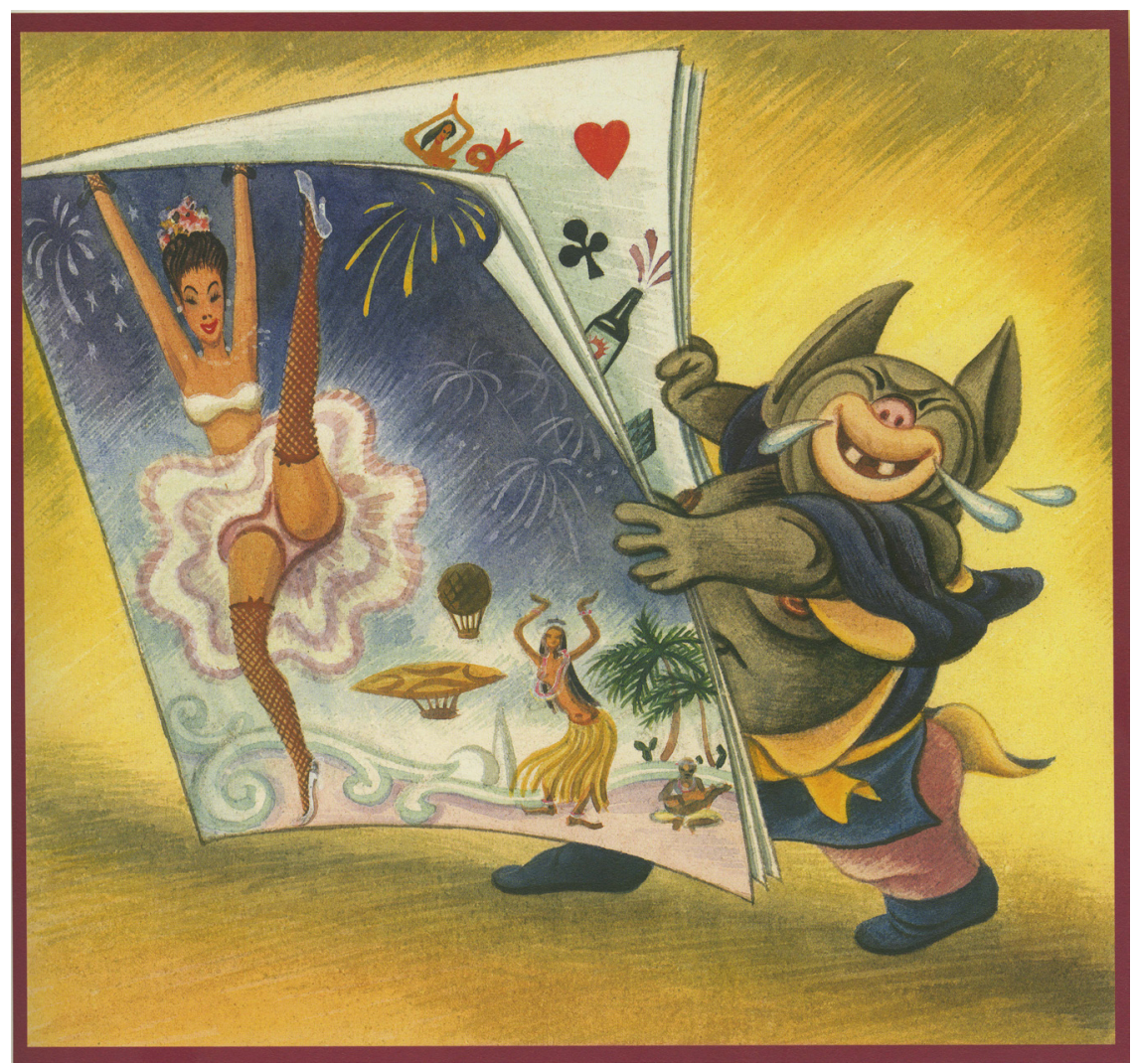

FIGURE 44. Pig reads the illustrated travel guide to the city of Dream Hedonia.

for the democratic pretensions held by proponents of "mass language" (dazhong yuyan) literature, which he describes as a "plaything of a leisured class" that not only fails to understand literature but treats the masses like "apes they can forcibly train." ${ }^{35}$ Pictorials, however, use images to attract people to the written word, making reading a pleasure rather than a chore. As Shao puts it, "Only after using pictures to satisfy their eyes and humor to relax their nerves can you irrigate their souls with ideas." ${ }^{36}$

Shao's defense of the pictorial magazine applies as well to Manhua Journey to the West. All the manhua artists who exhibited their work in the mid-1940s-such as Ding Cong, Huang Yao, and Liao Bingxiong-strove for a certain visual mass appeal to more effectively convey their political ideas. What sets Manhua Journey apart is the degree to which Zhang Guangyu transposes the visual idiom of the pictorial magazine to his satirical manhua. The art of manhua grew out of the illustrated magazine's kaleidoscopic aesthetic through the 1920s and 1930s. Zhang's Manhua Journey foregrounds that relationship, even elevates it to become 
the dominant aesthetic of the work as a whole, and in so doing it affirms the pictorial magazine's importance as a progressive artistic form in its own right.

In historical hindsight, however, Manhua Journey's celebration of the age of the Shanghai pictorial is tinged with irony. As Nicolai Volland has observed, by 1945, Shanghai's publishing industry was in the midst of far-reaching structural transformations. The foreign concession system that had helped shield writers and artists, including manhua artists, from Chinese government censorship had been abolished in 1943, thus diminishing the space for political expression through the periodical press. Yet at the same time, the popular, mass-market print genre whose format Manhua Journey to the West mimicked-picture-stories, or lianhuanhuarapidly expanded to dominate the urban print entertainment market and compete with serially published pictorial magazines. ${ }^{37}$ It is perhaps not surprising, then, that when Zhang Guangyu returned to Shanghai in 1946, he was unable to find steady work in the city that had sustained him and his career during the prewar decades. To continue their artistic mission, Zhang and other like-minded manhua artists took refuge in the relative freedom of a foreign-controlled city, Hong Kong. ${ }^{38}$ There, Zhang helped organize and lead a loose confederation of artists called the Human Studio (Renjian huahui). In November 1948, the Human Studio produced China's last pre-1949 manhua pictorial, This Is an Era of Manhua (Zhe shi yige manhua shidai). ${ }^{39}$ The young manhua artist Shen Tongheng (1914-2002), another refugee artist from Shanghai, wrote the following for the magazine's first and only issue: "This is an era of manhua, an era that manhua artists are striving with all their might to drive away in the hope of welcoming a time when, for lack of subject matter, manhua become impossible to create." ${ }^{40}$

Before another year was out, that new era had arrived, with the founding of the People's Republic of China in October 1949. Manhua did not become impossible to create, nor did its subject matter disappear. The role of manhua, however, adapted to sweeping transformations of the ideological landscape engineered under Mao's new regime. To understand how manhua changed, and why, we turn again to the illustrated magazine. 